\title{
EN LA CALLE Y MÁS ALLÁ: UNA APROXIMACIÓN SOCIOLÓGICA AL ARTE GRAFITTI. MARVIN RODRÍGUEZ VARGAS. SAN JOSÉ: EDITORIAL ARLEKÍN, 2016. 184 PÁGINAS
}

Sergio Villena Fiengo

Recibido: 06/03/2017 Aceptado: 17/03/2017

El libro de Marvin Rodríguez, jóven sociólogo costarricense, es un importante aporte a la incipiente sociología del arte que, desde hace años, viene configurándose poco a poco en la región centroamericana. Desde su título, notable por la economía de lenguaje, el autor establece con contundencia los alcances de su investigación. El título contiene tres - por así decir- declaraciones de principios: la primera se refiere al "arte grafitti" (y no simplemente al grafiti); la segunda propone un abordaje sociológico de esa práctica y la tercera trata al grafitti no solo en referencia a su habitual locus (los muros de la calle), sino que se propone abordar cuanto está "más allá" del objeto-imagen, es decir, la práctica social.

El abordaje del "arte grafiti" de este libro explora esa práctica artística en relación con tres dimensiones sociológicas, el grafitti como subcultura juvenil, como movimiento artístico y como un recurso para la revitalización urbana. El abordaje sociológico que realiza el autor es de tipo institucional y está sustentado, teóricamente, en los trabajos del sociólogo francés Pierre Bourdieu sobre el campo artístico y cultural y, metodológicamente, en el método del caso extendido del sociólogo norteamericano Michael Buroway.

El libro está organizado en cinco capítulos, además de la introducción y las conclusiones, en: I. Incursión al inframundo del grafitti costarricense, II. Excursus analítico, III. Las tensiones internas del arte grafitti, IV. El arte grafitti en el campo cultural y V. El grafitti en el campo del poder.

En el primer capítulo, Rodríguez plantea si el grafitti es, como a menudo suele señalarse desde ciertos ámbitos "oficiales" o "conservadores", una afrenta al espacio urbano. Al referirse a los motivos por los cuales eligió esta temática de investigación, el autor relata su transitar por la ciudad y su descubrimiento de que los grafiti implican una "reclamación de espacio, un desafío a la correcta política espacial y una intromisión (¿distorsión?) en la economía de la visibilidad y las audiencias". Así, "el grafitti no pretende vender nada y opera sin el beneplácito de los grupos que administran 
la configuración de la ciudad" (27). Además, este capítulo establece las coordenadas básicas de la investigación: "Planteo que la técnica de inscripción representa el puente que conecta el grafitti entendido como subcultura [juvenil] y el grafitti entendido como [subcampo del] arte" (31).

Finalmente, en este capítulo se delimitan los alcances empíricos de la investigación, al identificar a los participantes y los criterios de selección de los casos que trabaja. Para estudiar el grafiti como "subcultura" recurre a entrevistas de tres artistas del grafitti costarricenses (Mush, PN y Misha), y -como elemento de contraste- de dos visitantes mexicanos (Arty y Chikle). Al mismo tiempo, para abordar el carácter de "subcampo" artístico, apela a tres gestoras culturales (S.H., M.H. y K.R.), involucradas en la organización de eventos artísticos dirigidos a producir grafiti (De mi barrio a tu barrio, 2012; Casa y calle, 2013). Por último, para estudiar la relación entre el grafiti y el "campo de poder", el investigador analiza el Festival de Verano Transitarte, en sus ediciones 2011 y 2013, el cual es organizado por la Municipalidad de San José (entrevistó a E. V., funcionaria del Departamento de Servicios Culturales de la institución).

Antes de abordar esas tres dimensiones del grafiti (subcultural, subcampo cultural y recurso cultural), el autor desarrolla, en el segundo capítulo, un interesante "Excursus analítico", en el cual plantea las coordenadas teóricas básicas de su abordaje sociológico. Su referente principal es el prespectiva institucional de la sociología del arte que desarrolla Bourdieu, de quien toma su "sociología de las artes medias", elaborado por ese sociólogo francés en relación con la fotografía, para aplicarla a la práctica del grafitti, la cual asume, entonces, un carácter de "arte medio". Esa ubicación deriva de la estratificación de las prácticas culturales según su grado de legitimación y, tanto en el caso de la fotografía como en el del grafiti, se caracteriza por la tensión entre usos prácticos (subcultura) y suproducción estética (subcampo).

Así, según Rodríguez, lo particular del grafiti, en tanto "arte media", sería su ubicación fronteriza entre las subculturas juveniles y las prácticas artísticas, lo cual genera una tensión, pues la lógica de funcionamiento de esos dos ámbitos es distinta, ya que mientras el ethos subcultural (y el capital subcultural) deriva de la ilegalidad, la ocupación del espacio público y la irracionalidad económica, la legitimidad artística implica un reconocimiento institucional, esto lo convierte en una práctica consentida, privatizada y mercantilizada. Sin embargo, el autor evita substancializar el carácter del grafiti y prefiere hacer una historización de este, al señalar que, en sus orígenes, el grafitti en Costa Rica fue principalmente una forma subcultural juvenil; sin embargo, con el paso del tiempo ha tendido a desplazarse, no de forma total, hacia su constitución en subcampo artístico. Más adelante, señalará que pasará a ser considerado un "recurso cultural" para la revitalización urbana, lo cual introduce nuevas tensiones y matices a su práctica.

Rodríguez resume esa intensa discusión teórica, en la siguiente definición de grafitti artístico, el cual: 
Debe comprenderse como un espacio instersticial de relaciones y posiciones objetivas, en el que los pintores compiten animados por la illusio específica, sujetos a criterios de jerarquización interna y externa, esto es, a una forma determinada de creación y distribución del capital simbólico específico a lo interno del subcampo, y de capital sociocultural y económico en el campo cultural y del poder (67).

Precisamente, los capítulos siguientes están destinados a estudiar la dinámica interna del subcampo (capítulo 3), su relación con el campo cultural (capítulo 4) y sus vínculos con el campo del poder (capítulo 5).

Ahora bien, el tercer capítulo, "Las tensiones internas del arte grafitti", recurre al concepto de capital subcultural, elaborado por la socióloga canadiense Sarah Thorton, al cual considera un "principio rector del campo de producción" del grafiti. Con ese concepto, Rodríguez plantea que el arte grafitti no es "una comunidad homogénea y armónica", como usualmente tienden a considerar quienes lo consideran una "tribu urbana", sino más bien "un espacio social en el cual sus agente se encuentran en competencia permanente por el capital subcultural" (75). Desde esta perspectiva, las tomas de posición al interior del subcampo del grafitti están polarizadas en dos posturas, cada una de estas implica no solo posiciones axiológicas, sino también divergencias estéticas: el purismo (anclado en el ethos subcultural, con tendencia a lo críptico, la dependencia cultural y el mimetismo estético) y la disidente o heterodoxia (abierto a otras significaciones, con énfasis en las prácticas comunicativas, a lo autóctono y el acercamiento a lo popular).

El cuarto capítulo trata de "El grafitti en el campo cultural”, es decir, la relación entre el "arte grafiti" y la "cultura legítima". Rodríguez encuentra que, desde el año 2013, algunas instituciones encargadas del campo artístico "legítimo" han comenzado a organizar eventos artísticos -exposiciones e intervenciones públicas- con la participación de artistas de grafiti. La investigación presta especial atención a cómo los y las gestores culturales encargados de organizan este tipo de eventos legitiman la incorporacion del grafiti en las prácticas artísticas "legítimas", lo cual pasa por la discusión de cuestiones formales y no por una referencia al alcance "conceptual" del grafitti, pues sobre este recae la "sospecha" - desde el campo artístico legítimo- de que el grafitti es "un arte sin concepto", es decir, una práctica artística "naif", valorada principalmente por su "politicidad".

En este apartado, según el autor, el "flirteo" del arte grafitti con la institucionalidad artística no es visto con buenos ojos por los practicantes "ortodoxos" del grafiti, pues lo consideran una "traición a los valores de la subcultura”. Ese recelo, sin embargo, está presente entre los "agentes del arte contemporáneo", quienes "rehusan admitir que el arte grafitti pueda ser considerado arte, debido a la carencia de una serie de aspectos que determinan al "verdadero arte'" (149). Como sea, esos recelos mutuos no habrían impedido un acercamiento entre el "grafitti" y el "arte", lo cual -debido a la "simbiosis 
del arte grafitti con la vida cotidiana y el espacio público" (150)- habría "permitido hacer progresar la difnición de arte".

Para concluir, el quinto capítulo se refiere a "El arte grafitti en el campo del poder". Rodríguez señala cómo ciertas tendencias actuales en la políticas urbanas generadas a nivel mundial, principalmente aquellas referidas a "la ciudad creativa", han llevado a las autoridades municipales locales a considerar prácticas otrora perseguidas por "vandálicas" como un posible recurso cultural útil para la revitalización urbana. En este marco, la municipalidad de San José habría promovido la elaboración de una Política Cultural Municipal, así como establecido ciertos espacios de participación para los practicantes del grafiti; por ejemplo, el Festival de Verano Transitarte, considerado un esfuerzo por hacer que San José deje de ser un "pueblo fantasma" y convertirlo en una "ciudad creativa". El autor analiza el lugar del "arte grafiti" en la "ciudad creativa", con lo cual concluye que si bien las políticas municipales han creadoun "climafavorable" paraelreconocimientoparcialdeesa práctica, nohanlogrado establecer criterios suficientemente amplios de inclusión que también incorporen a otros actores en la dinámica de la ciudad, a quienes se les niega el reconocimiento de su derecho a la ciudad.

Como se señaló al iniciar esta resención, el libro de Marvin Rodríguez constituye un importante aporte a la sociología del arte y la cultura. En lo teórico, ya que realiza una interesante elaboración conceptual a partrir de Bourdieu (y en menor medida de Thorton y De Certeau), la cual no solo teoriza sobre las diversas y cambiantes características de esa práctica cultural, sino que además propone herramientas conceptuales para abordar el tema desde una perspectiva relacional con otros ámbitos de la vida social como las subculturas juveniles, el campo cultural legítimo y el campo de poder (especialmente municipales).

En lo metodológico, presenta una interesante aplicación del método del caso extendido de Buroway, además de un acercamiento metodológico complejo al análisis de la práctica del grafiti y de sus relaciones/tensiones con los otros ámbitos señalados. Finalmente, es un valioso aporte a la producción de conocimiento sociológico específico sobre Costa Rica, pues estudia desde una perspectiva, hasta ahora inédita, una práctica social poco abordada, permitiéndonos conocer más sobre nuestra realidad, a la vez que nos ofrece herramientas para pensar y actuar sobre la misma, de una manera sociológicamente informada. Quiero finalizar destacando que este libro es resultado de una tesis de licenciatura en sociología y, en ese sentido, merece especial reconocimiento, porque muestra el excelente nivel que puede alcanzar una investigación de ese tipo y el hecho de que muchas tesis de licenciatura son mucho más que un requisito académico, es decir, constituyen un importante aporte al conocimiento y, por tanto, merecen ser publicadas. Por ello, cabe felicitar a la editorial Arlekín por haber acogido este texto en su ya extensa y notable colección de ensayos. 
Sergio Villena Fiengo. Costarricense-boliviano. Doctorado en Estudios de la Sociedad y la Cultura (Universidad de Costa Rica), Maestría en Ciencias Sociales (FLACSO Sede México), Licenciatura en Ciencias Económicas (Universidad Mayor de San Simón, Cochabamba-Bolivia). Actual director del Instituto de Investigaciones Sociales de la Universidad de Costa Rica.

Contacto: sergio.villena@ucr.ac.cr

ORCID: 0000-0002-2864-8816 
